\title{
POTENSI EKSPANSIF PADA TANAH RESIDUAL DENGAN ATTERBERG LIMIT DAN $X$-RAY DIFFRACTION TEST UNTUK WILAYAH JAKARTA DAN SEKITARNYA
}

\author{
Evelyn$^{1}$ dan Chaidir A. Makarim ${ }^{2}$ \\ ${ }^{1}$ Program Studi Sarjana Teknik Sipil, Universitas Tarumanagara, Jl. Letjen S. Parman No.1 Jakarta \\ Email: wijaya.evelyn@rocketmail.com \\ ${ }^{2}$ Program Studi Sarjana Teknik Sipil, Universitas Tarumanagara, Jl. Letjen S. Parman No.1 Jakarta \\ Email: chaidir@untar.ac.id
}

\begin{abstract}
ABSTRAK
Tanah residual adalah tanah yang mengalami perubahan secara fisika dan kimia serta pengendapan pada tempat aslinya. Tanah ini kerap dikaitkan dengan potensi ekspansif yang dapat menyebabkan kerugian besar terutama pada infrastruktur di Indonesia. Sifat ekspansif perlu diantisipasi dengan pengujian tanah sebelumnya. Pengujian Atterberg Limit serta X-Ray Diffraction, menghasilkan nilai indeks plastisitas dan kandungan mineral yang dapat digunakan sebagai acuan analisa potensi ekspansif pada tanah. Pada penelitian ini pengujian dilakukan untuk mengetahui potensi ekspansif pada tanah residual di Jakarta dan sekitarnya, juga untuk mengetahui korelasi padanan antara nilai indeks plastisitas dengan kandungan mineral montmorillonite. Hasilnya dijumpai sampel dengan nilai indeks plastisitas yang tinggi tanpa mineral montmorillonite di dalamnya, sebaliknya dengan keberadaan kaolinite yang terdapat pada sampel dengan nilai IP yang tinggi. Hal ini menunjukkan bahwa keberadaan nilai indeks plastisitas yang tinggi tidak selalu bersamaan dengan kehadiran mineral montmorillonite. Selain itu, mineral kaolinite yang kerap dikaitkan dengan keberadaan potensi ekspansif sesungguhnya bukanlah mineral penyebab ekspansif. Kaolinite hanya dapat menjadi indikator nilai indeks plastisitas yang tinggi, namun bukan sebagai acuan sifat ekspansif, melainkan montmorillonite memiliki nilai aktivitas tinggi. Sebagai contoh diberikan analisa runtuhnya struktur pada salah satu underpass Bandara Internasional Soekarno Hatta, Tangerang. Kerusakan struktur akibat sifat ekspansif, dan keberadaan muka air tanah yang terlalu tinggi tidak hanya dapat merusak struktur bangunan, namun juga memakan korban jiwa.
\end{abstract}

Kata kunci : tanah residual, potensi ekspansif, atterberg limit test, $x$-ray diffraction

\section{PENDAHULUAN}

Indonesia sebagai negara yang banyak memiliki gunung berapi, menghasilkan tanah hasil pelapukan muntahan gunung berapi yang keseluruhan proses terjadi di tempat aslinya. Tanah ini disebut tanah residual. Tanah residual ini kerap disebut sebagai tanah yang memiliki potensi ekspansif, dimana ekspansif merupakan sifat tanah yang dapat mengembang serta menyusut seiring perubahan kadar air tanah. Hal ini dapat menimbulkan resiko kerusakan pada struktur di atasnya.

Penelitian mengenai batas cair (liquid limit) dan batas plastis (plastic limit) menunjukkan nilai indeks plastisitas, dimana nilai ini telah umum menjadi parameter potensi swelling (mengembang). Selain itu, kandungan mineral dalam tanah juga dapat menjadi parameter dalam menentukan jenis tanah. Kaolinite, illinite, dan montmorillonite adalah tiga mineral yang menjadi indikator penyebab potensi ekspansif pada tanah. Dari ketiga mineral itu, montmorillonite dipercaya sebagai mineral utama yang menyebabkan suatu tanah memiliki sifat ekspansif.

Namun pada kenyataannya, terkadang dijumpai tanah residual yang memiliki nilai indeks plastisitas tinggi, tetapi tidak memiliki satu pun dari mineral penyebab ekspansif. Hal ini menunjukkan bahwa potensi ekspansif pada tanah tidaklah selalu bergantung kepada kandungan ketiga mineral di atas. Pun dapat diperkirakan bahwa nilai indeks plastisitas bisa jadi tidak dapat menjadi parameter utama dalam penentuan potensi ekspansif yang absolut pada suatu tanah.

Di dalam penelitian ini, akan dilakukan penelitian terhadap sampel tanah residual di wilayah Jakarta dan sekitarnya. Penelitian akan menghasilkan data berupa nilai indeks plastisitas dari pengujian Atterberg Limit dan kandungan mineral dari pengujian X-Ray Diffraction pada masing-masing sampel. Seluruh data tersebut kemudian diharapkan dapat memaparkan potensi sifat ekspansif pada tanah residual di Jakarta dan sekitarnya. Adapula hubungan korelasi antara nilai indeks plastisitas dan kandungan mineral akan dibahas dalam penelitian ini. 


\section{TINJAUAN PUSTAKA}

Tanah secara umum didefinisikan sebagai agregat yang tidak tersementasi, bersifat loose (terberai), dengan mengalami pelapukan secara fisika dan kimia. Berdasarkan proses pembentukannya, tanah dibagi menjadi tanah sedimen dan tanah residual. Tanah residual adalah tanah yang mengalami pelapukan dan pengendapan di atas batuan induknya. Pembentukan tanah dipengaruhi oleh faktor-faktor penentu tanah seperti batuan induk, iklim, topografi, organisme, dan waktu. Jika hasil pelapukan masih berada di tempat asalnya, disebut residual soil. Tanah residual adalah hasil pelapukan (weathering) setempat pada batuan dasar. Pelapukan ini berjalan baik secara fisik maupun kimiawi, dengan akibat batuan tersebut diubah sifatnya sampai akhirnya menjadi tanah (Wesley, 1998).

Tanah ekspansif merupakan salah satu jenis tanah yang ada berdasarkan perubahan strukturnya. Yang dimaksud tanah ekspansif adalah tanah yang bisa mengalami perubahan volume akibat perubahan kadar air dalam tanah. Terdapat dua faktor utama yang perlu diindentifikasi sebelumnya dalam menentukan karakteristik potensial menyusut mengembang dalam sebuah proyek ataupun gedung ataupun sebuah jalan tol, yaitu parameter tanah yang mengacu kepada sifat ekspansif atau menyusut - mengembang, dan kondisi lingkungan yang dapat berkontribusi dalam perubahan kandungan di dalam tanah tersebut (Nelson \& Miller, 1992).

Pendorong potensi ekspansif pada tanah dapat berasal dari karakteristik tanah yang mempengaruhi sifat dasar medan gaya internal, dapat pula oleh faktor lingkungan yang mempengaruhi perubahan yang mungkin terjadi pada sistem gaya internal (internal force system), serta keadaan stres. Mineral dalam tanah menjadi penyebab yang dapat dikatakan sebagai penyebab utama. Potensi mengembang tersebut diperoleh dari besarnya activity (Ac), yang didapat dengan persamaan yang dikemukakan oleh Skempton sebagai berikut:

$$
\operatorname{Aktivitas}(\mathrm{Ac})=\frac{\mathrm{PI}}{\mathrm{c}-10}
$$

Keterangan:

$$
\begin{array}{ll}
\mathrm{c} & : \text { Presentase fraksi lempung }<0.001 \\
\mathrm{Ac}>1.25 & : \text { Tanah bersifat aktif dan ekspansif } \\
0.75<\mathrm{Ac}<1.25 & : \text { Tanah digolongkan normal } \\
\text { Ac }<0.75 & : \text { Tanah digolongkan tidak aktif }
\end{array}
$$

Adapula hubungan mineral dengan aktivitas tanah telah diteliti oleh Skempton dan Mitchell, seperti pada tabel di bawah ini.

Tabel 1. Hubungan Mineral dengan Aktivitas Tanah (Skempton and Mitchell, 1976)

\begin{tabular}{|c|c|}
\hline Mineral & Aktivitas \\
\hline Na-Montmorillonite & $4-7$ \\
\hline Ca-Montmorillonite & 1.5 \\
\hline Illite & $0.5-1.3$ \\
\hline Kaolinite & $0.3-0.5$ \\
\hline Halloysite (dehydrated) & 0.5 \\
\hline Halloysite (hydrated) & 0.1 \\
\hline Attapilgite & $0.5-1.2$ \\
\hline Allophane & $0.5-1.2$ \\
\hline Mica & 0.2 \\
\hline Calcite & 0.2 \\
\hline Quartz & 0 \\
\hline
\end{tabular}

Dari tabel di atas, Skempton dan Mitchel menjelaskan bahwa untuk aktivitas yang lebih besar dari 1.25 digolongkan aktif dan sifatnya ekspansif, aktivitas antara 0.75 - 1.25 digolongkan normal, sedangkan yang kurang dari 0.75 digolongkan tidak aktif.

Parameter indeks plastisitas (IP) yang tinggi pun sering dikaitkan dengan potensi ekspansif. Di bawah ini tabel yang menunjukkan batas nilai IP terhadap potensi ekspansif pada tanah. 
a. Kriteria Raman

Tabel 2. Kriteria Tanah Ekspansif Berdasarkan PI dan SI (Raman, 1967 dalam Das, 1995)

\begin{tabular}{|c|c|c|}
\hline $\begin{array}{c}\text { Plasticity Index } \\
(\%)\end{array}$ & $\begin{array}{c}\text { Shrinkage } \\
\text { Index }(\%)\end{array}$ & Degree of Exapansion \\
\hline$<12$ & $<15$ & Low \\
\hline $12-23$ & $15-30$ & Medium \\
\hline $23-30$ & $30-40$ & High \\
\hline$>30$ & $>40$ & Very High \\
\hline
\end{tabular}

b. Kriteria Chen

Tabel 3. Kriteria Pengembangan Berdasarkan PI (Chen, 1988 dalam Das, 1995)

\begin{tabular}{|c|c|}
\hline Plasticity Index $(\%)$ & Swelling Potential \\
\hline $0-15$ & Low \\
\hline $10-35$ & Medium \\
\hline $20-35$ & High \\
\hline$>35$ & Very High \\
\hline
\end{tabular}

c. Kriteria Snethen

Tabel 4. Klasifikasi Potential Swelling (Snethen et. al, 1977 dalam Das, 1995)

\begin{tabular}{|c|c|c|c|}
\hline LL (\%) & PI (\%) & $\begin{array}{c}\text { Potential } \\
\text { Swelling }(\%)\end{array}$ & $\begin{array}{c}\text { Potential Swelling } \\
\text { Classification }\end{array}$ \\
\hline$>60$ & $>35$ & $>1.5$ & High \\
\hline $50-60$ & $25-35$ & $0.5-1.5$ & Medium \\
\hline$<50$ & $<25$ & $<0.5$ & Low \\
\hline
\end{tabular}

\section{METODOLOGI PENELITIAN}

Penelitian terhadap potensi ekspansif pada tanah residual dimulai dengan pengambilan 13 sampel tanah (disturbed) di wilayah Jakarta dan sekitarnya. Jumlah banyaknya tanah untuk setiap sampel diambil secukupnya sesuai dengan keperluan pengujian Atterberg Limit dan X-Ray Diffraction. Sampel tanah masing-masing dimasukkan ke dalam kantong plastik kedap udara dan disimpan sementara di Laboratorium Mekanika Tanah Universitas Tarumanagara.

Setelah sampel tanah terkumpul, dilakukan tahap pengujian Atterberg Limit di Laboratorium Mekanika Tanah Universitas Tarumanagara. Atterberg Limit adalah sebuah pengujian untuk memperoleh nilai indeks plastisitas. Pengujian dilakukan dengan menggunakan alat Cassagrande, dengan ketentuan mengikuti standar ASTM.

Sampel dengan nilai plastisitas yang tinggi (lebih dari 30\%) kemudian dilakukan pengujian X-Ray Diffraction di laboratorium milik Perusahaan Sucofindo. Pengujian ini bertujuan untuk menunjukkan kandungan mineral yang terkandung di dalam setiap sampel tanah tersebut. Data-data yang diperoleh dari kedua pengujian di atas kemudian dianalisa untuk masing-masing sampel.

\section{ANALISA DAN PEMBAHASAN}

\section{Sampel Pengujian}

Sampel tanah berjumlah 13 sampel distureb (terganggu), dengan daftar lokasi sampel seperti di bawah ini.

1. Jakarta Pusat - nama sampel "TVRI 1" (seberang Menara TVRI)

2. Jakarta Pusat - nama sampel "TVRI 2" (seberang Menara TVRI)

3. Fatmawati, Jakarta Selatan - nama sampel "Fatmawati" (tanah urug untuk taman Gedung M, UNTAR 1)

4. Tanjung Priok, Jakarta Utara - nama sampel "Tanjung Priok" (wilayah tanah reklamasi)

5. Jababeka, Cikarang, Bekasi - nama sampel "Jababeka" (wilayah industri pabrik di Jababeka)

6. Meikarta, Cikarang, Bekasi - nama sampel "Meikarta" (wilayah proyek Meikarta)

7. Delta Mas, Cikarang, Bekasi - nama sampel "Delta Mas" (depan Sakura Hotel)

8. Jatiasih, Bekasi - nama sampel "Jatiasih" (komplek perumahan di Jatiasih)

9. Parung, Bogor, Jawa Barat - nama sampel "Parung Bogor" (di bawah kaki Gunung Sindur)

10. Sentul, Jawa Barat - nama sampel "Sentul” (wilayah proyek PUSDIKLAT Buddha) 
11. Bandara Internasional Soekarno Hatta, Tangerang - nama sampel "Soetta 1" (Jl. Parameter Selatan, underpass bandara, tanah bagian atas)

12. Bandara Internasional Soekarno Hatta, Tangerang - nama sampel "Soetta 2" (Jl. Parameter Selatan, underpass bandara, tanah bagian bawah)

13. Bandara Internasional Soekarno Hatta, Tangerang - nama sampel "Soetta 3" (J1. Parameter Selatan, underpass bandara, tanah bagian longsor)

\section{Analisa Potensi Ekspansif}

Pengujian Atterberg Limit dilakukan untuk seluruh sampel, lalu sampel dengan nilai indeks plastisitas mendekati dan atau di atas 30\% dilakukan pengujian X-Ray Diffraction (XRD). Juga dilakukan pengujian XRD untuk ketiga sampel yang diperoleh dari underpass bandara untuk keperluan analisa keruntuhan. Penulis memakai Kriteria Chen sebagai acuan kategori menurut nilai IP, serta kandungan mineral pada masing-masing sampel yang diuji. Di bawah ini tabel hasil rekapitulasi dari kedua pengujian.

Tabel 5. Tabel Rekapitulasi Hasil Pengujian Sampel Tanah

\begin{tabular}{|c|c|c|c|}
\hline Nama Sampel & $\begin{array}{c}\text { Indeks } \\
\text { Plastisitas }\end{array}$ & $\begin{array}{c}\text { Swelling } \\
\text { Potential } \\
\text { menurut IP } \\
\text { (Chen, 1988) }\end{array}$ & Kandungan Mineral \\
\hline TVRI 1 & 28.1446 & High & $\begin{array}{c}\text { Kaolinite (34\%), Rhodochrosite (5\%), Hematie (10\%), } \\
\text { Magnetite (20\%), Goethite (13\%), Albite (7\%), Quartz (11\%) }\end{array}$ \\
\hline TVRI 2 & 34.8529 & High & $\begin{array}{c}\text { Kaolinite (27\%), Rhodochrosite (5\%), Hematie (9\%), } \\
\text { Magnetite (9\%), Gothite (15\%), Albite (8\%), Quartz (27\%) }\end{array}$ \\
\hline Fatmawati & 33.6392 & High & $\begin{array}{c}\text { Kaolinite (29\%), Rhodochrosite (4\%), Hematie (9\%), Calcite } \\
\text { (4\%), Magnetite (18\%), Goethite (14\%), Albite (6\%), Quartz } \\
\text { (16\%) }\end{array}$ \\
\hline Tanjung Priok & 37.0379 & Very High & $\begin{array}{c}\text { Kaolinite (10\%), Rhodochrosite (9\%), Hematie (5\%), Calcite } \\
\text { (8\%), Albite (7\%), Quartz (61\%) }\end{array}$ \\
\hline Jababeka & 46.5020 & Very High & $\begin{array}{c}\text { Montmorillonite (11\%), Kaolinite (9\%), Calcite (Trace), } \\
\text { Albite (Trace), Quartz (80\%) }\end{array}$ \\
\hline Meikarta & 45.3435 & Very High & $\begin{array}{c}\text { Montmorillonite (12\%), Kaolinite (8\%), Calcite (Trace), } \\
\text { Albite (Trace), Quartz (80\%) }\end{array}$ \\
\hline Delta Mas & 66.9587 & Very High & $\begin{array}{c}\text { Montmorillonite (16\%), Kaolinite (10\%), Calcite (Trace), } \\
\text { Albite (Trace), Quartz (75\%) }\end{array}$ \\
\hline Jatiasih & 15.2539 & Medium & - (tidak diuji) \\
\hline Parung Bogor & 21.3851 & Medium-High & - (tidak diuji) \\
\hline Sentul & 19.5562 & Medium & - (tidak diuji) \\
\hline Soetta 1 & 21.7511 & Medium-High & $\begin{array}{c}\text { Montmorillonite (7\%), Kaolinite (5\%), Rhodochrosite (5\%), } \\
\text { Calcite (4\%), Cristobalite (26\%), Albite (26\%), Quartz (27\%) }\end{array}$ \\
\hline Soetta 2 & 24.0813 & Medium - High & $\begin{array}{c}\text { Montmorillonite (10\%), Kaolinite (6\%), Hematie (5\%), } \\
\text { Rhodochrosite (5\%), Calcite (5\%), Cristobalite (25\%), Albite } \\
\text { (25\%), Quartz(19\%) }\end{array}$ \\
\hline Soetta 3 & 29.1106 & High & - (tidak diuji) \\
\hline
\end{tabular}

Berdasarkan hasil pengujian Atterberg Limit dan X-Ray Diffraction yang telah dilakukan, maka dapat dianalisa potensi ekspansif dimiliki oleh masing-masing sampel dengan besar potensi yang berbeda-beda. Analisa potensi pada penelitian ini hanya mengacu kepada dua indikator, yaitu nilai indeks plastisitas dan keberadaan mineral montmorillonite. Maka tanah yang tidak memiliki mineral montmorillonite dianggap tidak memiliki potensi ekspansif sama sekali.

Tanah dengan kategori "medium" serta memiliki kandungan montmorillonite mengindikasikan potensi yang swelling yang rendah. Tanah dengan kategori "high" serta memiliki kandungan montmorillonite, mengindikasikan adanya potensi swelling yang menengah. Tanah dengan kategori "very high" serta memiliki kandungan montmorillonite, mengindikasikan adanya potensi swelling yang tinggi. 
Apabila dilihat dari analisis di atas, maka didapati potensi ekspansif pada masing-masing sampel adalah sebagai berikut :

1. Kategori Tidak Ada Potensi Ekspansif : TVRI 1, TVRI 2, Fatmawati, Tanjung Priok, Jatiasih, Parung, Sentul

2. Kategori Potensi Ekspansif Rendah : Soetta 1, Soetta 2

3. Kategori Potensi Ekspansif Menengah : Soetta 3 (asumsi hasil XRD menyerupai hasil sampel Soetta 1 dan Soetta 2)

4. Kategori Potensi Ekspansif Tinggi : Jababeka, Meikarta, Delta Mas

Berdasarkan hasil pengujian pun dapat dilihat bahwa nilai indeks plastisitas yang tinggi tidak selalu dijumpai mineral montmorillonite, namun selalu memiliki kaolinilte di dalamnya.

Di bawah ini adalah gambar yang memperlihatkan hubungan nilai indeks plastisitas dengan keberadaan mineral montmorillonite dan kaolinite pada masing-masing sampel.

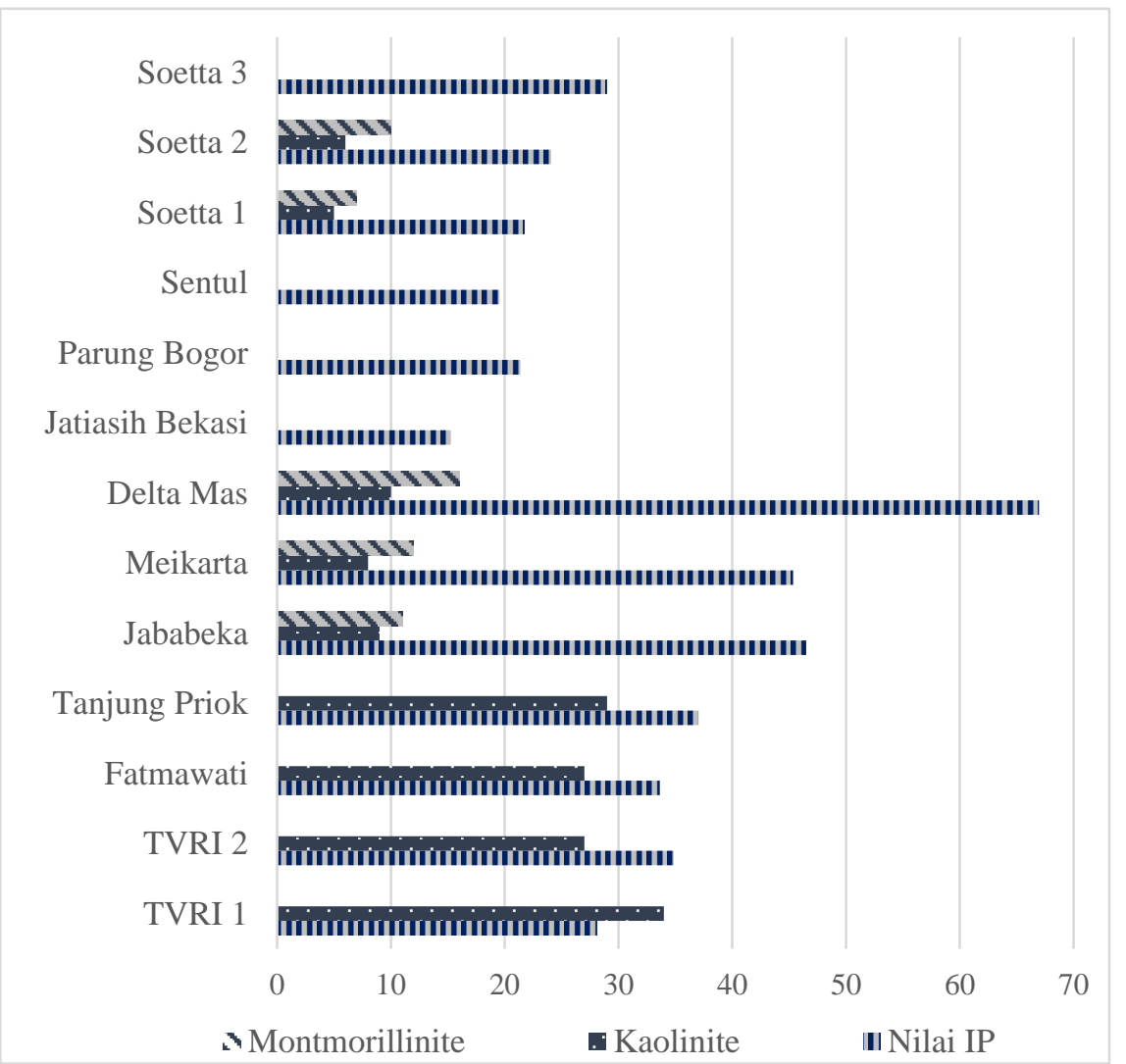

Gambar 1. Hubungan Indeks Plastisitas, Montomorillonite, dan Kaolinite pada Sampel Tanah

Berdasarkan gambar di atas, diperoleh pengertian bahwa bersamaan dengan nilai indeks plastisitas yang tinggi selalu ditemukan mineral kaolinite, namun lain halnya dengan mineral montmorillonite. Ini menunjukkan bahwa korelasi atau hubungan nilai IP sejajar dengan mineral kaolinite, namun berbeda dengan montmorillonite yang tidak selalu berada di tanah yang memiliki IP tinggi.

\section{Contoh Kasus Kegagalan Konstruksi pada Tanah Ekspansif dengan Analisa Pemograman Plaxis 8.2}

Tanah ekspansif telah banyak menimbulkan masalah kerusakan struktur di berbagai tempat, tak terkecuali di Indonesia. Salah satu contoh adalah kasus longsor pada salah satu underpass Bandara Internasional Soekarno Hatta, pada tanggal 5 Februari 2018 pukul 17.20 WIB.

Salah satu kegagalan struktur yang terjadi di Tangerang, tepatnya pada Kilometer $8+6 / 7$, Jalan Parameter Selatan ini sampai memakan korban serta sebuah kendaraan yang rusak berat. Berikut adalah gambar yang menunjukkan gambar lokasi sebelum longsor. 


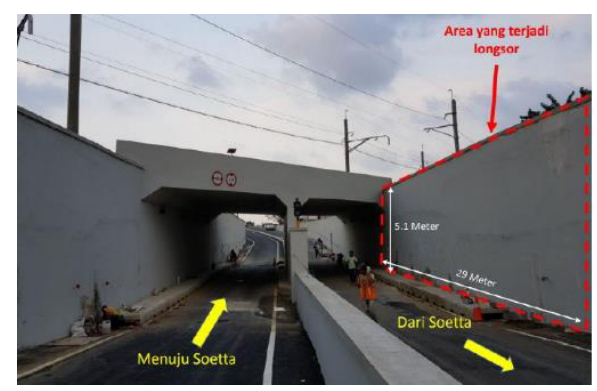

Gambar 2. Lokasi Underpass Sebelum Longsor (Kementerian Pekerjaan Umum dan Perumahan Direktorat Jenderal Bina Marga, 2018)

Sampel tanah untuk pengujian diperoleh langsung dari tempat kejadian, dengan persetujuan Kapolres Bandara, diambil 3 sampel terganggu (disturb). Tanah di bagian atas underpass (sampel Soetta 1), bagian bawah (sampel Soetta 2), serta tanah yang jatuh longsor (sampel Soetta 3 ).

Analisa struktur ini menggunakan program Plaxis 8.2, dengan menggunakan desain struktur dinding penahan tanah yang sesuai dengan desain struktur asli sebelum tanah longsor. Di bawah ini adalah gambar yang merupakan desain struktur dinding penahan tanah pada lokasi underpass.

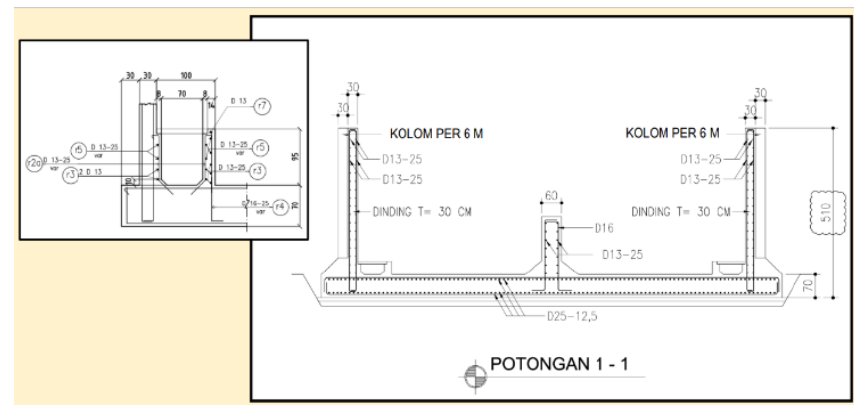

Gambar 3. Desain Struktur Dinding Penahan Tanah pada Lokasi Underpass (Kementerian Pekerjaan Umum dan Perumahan Direktorat Jenderal Bina Marga, 2018)

Sampel yang diambil dari lokasi kejadian terdiri dari 3 sampel, namun dianggap sampel Soetta 1 mewakili bagian atas dan sampel Soetta 2 mewakili bagian bawah dari struktur tanah. Asumsi bawah setinggi 3 meter dari permukaan tanah dasar, serta tanah atas setinggi 2.1 meter di atas tanah bagian bawah. Pengujian yang dilakukan berupa pengujian Atterberg Limit untuk mendapat nilai indeks plastisitas (IP), serta data pendukung lainnya diperoleh dari hasil engineering adjustment.

Nilai friction angle didapat dari pendekatan menurut Wesley (2008), nilai gamma saturated diperoleh dari persamaan berikut ini (Lobbezoo, J.P. and Vanapalli, S.K., 2002):

$$
\gamma=4.64(I P)+0.71
$$

Dari persamaan di atas, didapatkan nilai gamma saturated untuk sampel Soetta 1 adalah 1.72 dan untuk sampel Soetta 2 adalah 1.83. Gamma unsaturated diperoleh dengan nilai gamma saturated yang dibagi dengan nilai 1.35. Kemudian pada analisa ini digunakan perhitungan mohr-coulomb dalam keadaan drained, dengan nilai modulus young sebesar $4000 \mathrm{KN} / \mathrm{m}^{2}$ dan nilai poisson ratio sebesar 0.4, nilai ini diperoleh dari hasil penelitian Lambe dan Whitman pada tahun 1969 .

Data yang digunakan sebagai berikut:

1. Sampel Soetta 1 (Tanah Bagian Atas)

- Tebal Lapisan $=2,1$ meter

- Nilai IP = 21,7511\%

- Nilai LL $=53,2135 \%$

- Nilai Friction Angle = $12^{\circ}$

- Nilai Gamma Saturated =1,72 KN/m³

- Nilai Gamma Unsaturated =1,30 KN/m $\mathrm{m}^{3}$

- Nilai Modulus Young = 4000 KN/m²

- Nilai Poisson Ratio = 0,4
- Pressure = Gamma $\mathrm{x}$ Kedalaman $=1,72 \mathrm{x}$ $2,1=36,12 \mathrm{KN} / \mathrm{m}^{2}$

2. Sampel Soetta 2 (Tanah Bagian Bawah)

- Tebal Lapisan = 3,0 meter

- Nilai IP = 24,0813\%

- Nilai LL = 56,041\%

- Nilai Friction Angle $=12^{\circ}$

- Nilai gamma saturated $=1,83 \mathrm{KN} / \mathrm{m}^{3}$

- Nilai gamma unsaturated $=1,37 \mathrm{KN} / \mathrm{m}^{3}$ 
- Nilai Modulus Young = $4000 \mathrm{KN} / \mathrm{m}^{2}$

- Nilai Poisson Ratio = 0,4
- Pressure $=$ Gamma $\mathrm{x}$ Kedalaman $=1,83 \mathrm{x}$ $3,0=54,90 \mathrm{KN} / \mathrm{m}^{2}$

Data-data diatas kemudian dimasukkan ke dalam program Plaxis 8.2, dilakukan 2 kali pengujian dengan perbedaan pada tingkat muka air tanah (MAT). Tegangan atau pressuse yang terjadi pada struktur juga dibuat secara merata sejajar penuh membentuk persegi panjang, sesuai dengan pendekatan perhitungan tegangan pada tanah ekspansif menurut D.G. Fredlund, H. Rahardjo, dan M.D. Fredlund.

Di bawah ini gambar yang merupakan kondisi awal dari struktur tanah dan dinding penahan tanah dengan program, sebelum pengujian dilakukan.

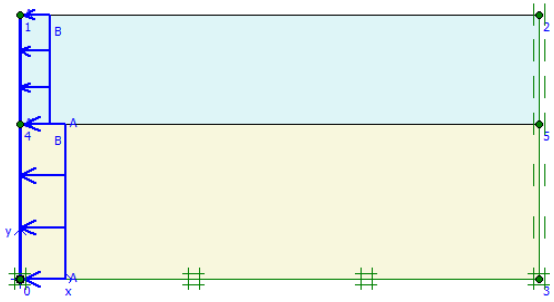

Gambar 4. Desain Struktur DPT pada Underpass dengan Program Plaxis

Pada pengujian pertama, MAT berada pada ketinggian 5.055 meter di atas permukaan tanah bawah. Dilakukan proses perhitungan untuk mendapatkan hasil akhir pengujian.

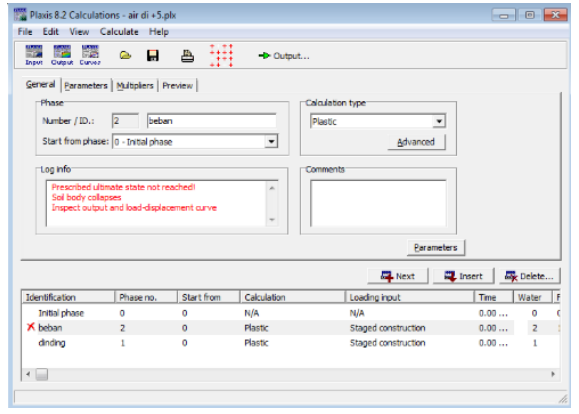

Gambar 5. Hasil Perhitungan Pengujian Pertama dengan MAT +5.055

Pada hasil di atas, terlihat bahwa beban yang diterima terlalu besar mengakibatkan dinding penahan tanah tidak mampu menahan tanah. Di bawah ini, gambar di bawah adalah gambar output dari struktur pada pengujian pertama.

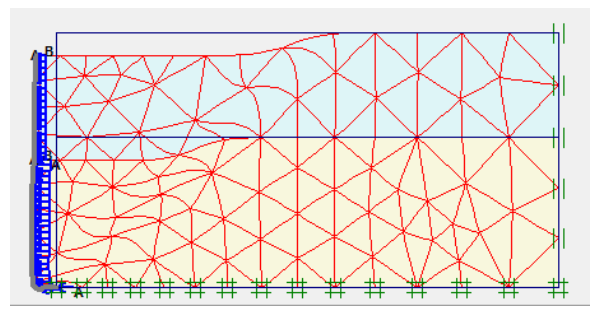

Gambar 6. Hasil Output pada Pengujian Pertama dengan MAT +5.055

Pada pengujian kedua, MAT berada pada ketinggian 2.057 meter di atas permukaan tanah bawah. Dilakukan proses perhitungan untuk mendapatkan hasil akhir pengujian, di bawah ini gambar yang merupakan hasil perhitungan pada pengujian kedua. 

dan Sekitarnya

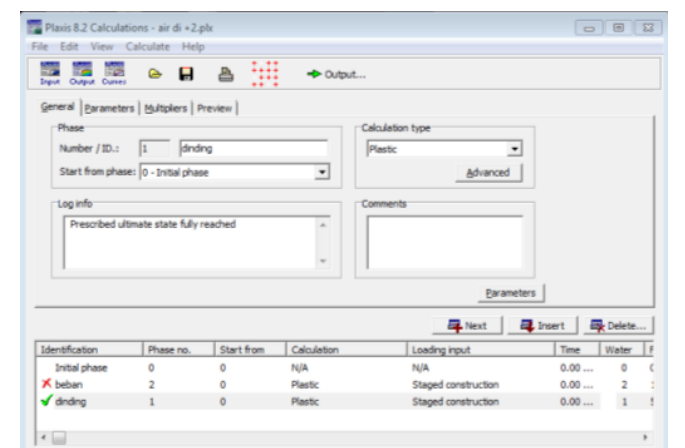

Gambar 7. Hasil Perhitungan Pengujian Pertama dengan MAT +2.057

Pada hasil di atas, terlihat dinding telah berada pada keadaan maksimal dalam menahan beban. Ini menunjukkan bahwa dalam kondisi tersebut dinding masih mampu menahan beban, namun akan rusak apabila muka air tanah berada di atas 2.057 meter. Pada output program pun dinding tidak mengalami kerusakan dan tetap berdiri seperti semula, seperti pada gambar di bawah ini.

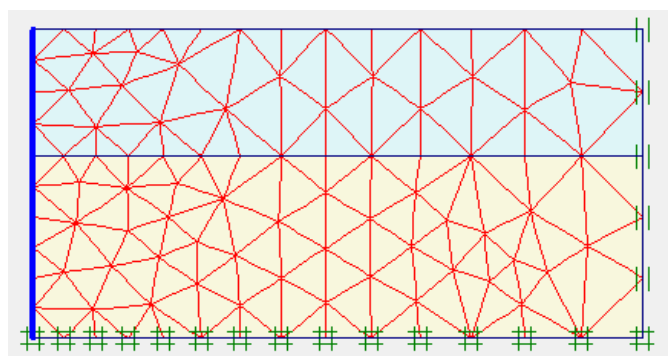

Gambar 8. Hasil Output pada Pengujian Pertama dengan MAT +2.057

Berdasarkan analisa di atas, dapat diperkirakan bahwa runtuhnya underpass diakibatkan oleh beberapa faktor antara lain sebagai berikut. Desain struktur yang digunakan sebagai dinding penahan tanah tidak cocok digunakan untuk tanah yang memiliki sifat ekspansif. Hanya dengan ketebalan $30 \mathrm{~cm}$, dinding tersebut dibuat setinggi 5,1 meter dan panjang berpuluh-puluh meter. Maka dengan sifat ekspansif yang dapat mengembang pada saat musim hujan, tekanan yang diberikan tidak mampu ditahan oleh dinding apabila muka air tanah sudah melebihi 2 meter dari permukaan tanah.

Muka air tanah sangat berpengaruh di dalam sifat ekspansif pada tanah, mengingat runtuhnya dinding adalah pada awal bulan Februari, maka dapat dikatakan bahwa curah hujan yang besar menyebabkan kenaikan muka air tanah secara perlahan. Maka berdasarkan analisa, muka air tanah yang naik perlahan serta sifat ekspansif ini yang kemudian membuat dinding penahan tersebut runtuh.

Keruntuhan dinding penahan tanah ini bukanlah menjadi kasus pertama di Indonesia, yang dimana tanah ekspansif menjadi salah satu penyebabnya. Hotel Hilton di Surabaya yang berdiri di atas tanah ekspansif misalnya, telah menimbulkan kerugian mencapai puluhan miliar rupiah. Tanah di daerah Cikarang, Jawa Barat, memiliki kandungan tanah ekspansif yang telah banyak merugikan banyak pihak. Jalan Tol Trans-Jawa yang berada di sekitar Pantura pun memiliki tanah ekspansif yang dalam kenyataannya pun telah merugikan negara. Contoh di atas menunjukkan betapa pentingnya potensi ekspansif pada tanah untuk diperhatikan sebelum pembangunan infrastruktur dikerjakan.

\section{KESIMPULAN}

Tanah residual merupakan tanah yang mengalami pelapukan serta pengendapan pada tempat aslinya. Tanah ini banyak terdapat di Indonesia dikarenakan kondisi nusantara yang memiliki banyak gunung berapi. Tanah residual kerap dihubungkan dengan sifat ekspansif, dimana sifat ini dapat menyebabkan potensi kerusakan yang besar apabila tidak ditangani dengan baik.

Dari hasil pengujian Atterberg Limit dan X-Ray Diffraction, diperoleh nilai indeks plastisitas serta persentase kandungan mineral yang berbeda-beda pada setiap sampelnya. Mineral montmorillonite telah menjadi mineral penentu sifat ekspansif dikarenakan memiliki nilai aktivitas yang tinggi (4-7), lain halnya dengan kaolinite yang hanya memiliki nilai 0.3-0.5 sehingga tidak dianggap sebagai penentu sifat ekspansif pada tanah.

Berdasarkan hasil dari seluruh pengujian yang dilakukan, didapati bahwa sampel TVRI 1, TVRI 2, Fatmawati, Tanjung Priok, Jatiasih, Parung Bogor, dan Sentul tidak memiliki potensi ekspansif. Sampel Soetta 1 dan Soetta 2 
memiliki potensi ekspansif yang rendah. Sampel Soetta 3 memiliki potensi ekspansif yang menengah. Dan sampel Jababeka, Meikarta, serta Delta Mas memiliki potensi ekspansif yang tinggi.

Hubungan antara nilai indeks plastisitas dan mineral montmorillonite tidak selalu berpadanan, seperti pada sampel TVRI 1, TVRI 2, Fatmawati, dan Tanjung Priok yang memiliki nilai IP cukup tinggi namun tidak memiliki kandungan montmorillonite. Sedangkan hubungan nilai indeks plastisitas berbanding lurus atau selaras dengan keberadaan mineral kaolinite, seperti terdapat pada seluruh sampel teruji.

Hal ini menjelaskan bahwa mineral kaolinite yang sering dikaitkan dengan keberadaan potensi ekspansif tidaklah sepenuhnya benar. Kaolinite dapat menjadi indikasi kandungan indeks plastisitas yang tinggi, namun tidak dapat menjadi acuan untuk menentukan potensi ekspansif. Maka nilai indeks plastisitas sejatinya dapat menjadi gerbang awal dalam mengindikasikan potensi ekspansif, tetapi perlu ada pengujian selanjutnya untuk mengetahui apakah tanah tersebut memiliki kandungan montmorillonite (maupun mineral smectite lainnya) yang menjadi pemicu utama sifat ekspansif.

Kegagalan struktur akibat tanah ekspansif pun banyak terjadi di luar maupun di dalam negeri. Contoh kasus telah dibahas pada bab 4, dimana terjadi longsor pada salah satu underpass di Bandara Internasional Soekarno Hatta, yang sampai memakan korban. Longsor tersebut tidak lepas dari pengaruh sifat ekspansif yang merusak. Berdasarkan pada pembahasan di bab sebelumnya, dengan kondisi tanah ekspansif dan dinding penahan tanah yang tidak besar, longsor dapat terjadi apabila muka air tanah terdapat di atas dua meter dari permukaan tanah. Hal ini juga menunjukkan keberadaan muka air tanah sangat berpengaruh di dalam proses desain struktur bangunan.

\section{DAFTAR PUSTAKA}

Chen, Fu Hua. Foundations on Expansive Soils. Michigan: Elsevier, 1988.

Das, Braja M. Mekanika Tanah 1. Jakarta: Erlangga, 1995.

Fang, H. Y., ed. Foundation Engineering Handbook. By Hans F. Winterkom. 1975. Boston: Kluwer Academic Publishers, 1991.

Fredlund, D. G., Rahardjo, H., and Fredlund, M. D. Unsaturated Soil Mechanics in Engineering Practice. Hoboken, New Jersey: John Wiley and Sons, 2012.

Hensen, Emiel J.M., and Smit B. Why Clays Swell. Jurnal Phys. Chem. (Sept 2002).

Husain, Ratna. Geokimia Mineral Lempung dan Implikasinya Terhadap Gerakan Tanah. Disertasi, Universitas Hasanuddin, 2015.

Kementerian Pekerjaan Umum dan Perumahan Rakyat Direktorat Jenderal Bina Marga. Kompilasi Kecelakaan Konstruksi Pembangunan Jembatan Tahun 2017 - 2018. Jakarta: Direktorat Jembatan, 2018.

King, Hobart M. Expansive Soils and Expansive Clay: The Hidden Force Behind Basement and Foundation Problems (On-Line). Tersedia di www: https://geology.com/articles/expansive-soil.shtml (24 Februari 2018).

Lambe, T. W., and Whitman, R. V. Soil Mechanics. New York: Wiley, 1969.

Lobbezoo, J. P., and Vanapalli, S.K. A Simple Technique for Estimating The Coefficient of Permeability of Unsaturated Soils. Canada, 2002.

Makarim, Chaidir A. Forensic Geotechnical Practice in Indonesia: Case Histories of An Alternative Dispute Resolution Awards di dalam buku "The Latest Development in Civil Engineering: A Book to Honor the 80th Birthday of Prof. Dr. Ir. Wiratman Wangsadinata", WiTness Press, Jakarta, 2015.

Mitchell, J.K. Fundamental of Soil Behavior. New York: John Wiley and Sons, 1976.

Nelson, J. D., and Miller, D. J. Expansive Soils: Problems and Practice in Foundation and Pavement Engineering. Canada: John Wiley and Sons, 1992.

Skempton, A.W. The Colloidal "Activity” of Clays. England: Thomas Telford Publishing, 1984.

Spagnoli, G., Sridharan, A., Oreste, P., Bellato, D., and Matteo, L. D: Statistical Variability of The Correlation Plasticity Index Versus Liquid Limit for Smectite and Kaolinite. India, 2018.

Sumarli, I., dan Makarim, C. A. 2016. Analisis Value Engineering Berbasis Risiko Untuk Mengatasi Faktor Ketidakpastian Parameter Geoteknik, Studi Kasus: Jalan Tol. Seminar Nasional Teknologi dan Sains (SNTS) II 2016, Teknik Sipil Universitas Tarumanagara, Jakarta.

Velde, B., and Barre P. Soils, Plants and Clay Minerals: Mineral and Biologic Interactions. German: Springer Heidelberg Dordrecht London New York, 2010.

Velde, B., and Meunier A. The Origin of Clay Minerals in Soils and Weathered Rocks. German: Springer-Verlag Berlin Heidelberg, 2008.

Wesley, L. D. Fundamentals of Soil Mechanics for Sedimentary and Residual Soils. Hoboken, New Jersey: John Wiley and Sons, 2009.

Wesley, L. D. Geotechnical Engineering in Residual Soils. Hoboken, New Jersey: John Wiley and Sons, 2010. 